\title{
Glucose-6-phosphate dehydrogenase (G6PD) mutations in Myanmar: G6PD Mahidol (487G $>A$ ) is the most common variant in the Myanmar population
}

Received: 22 April 2004/ Accepted: 12 July 2004/Published online: 3 September 2004

(C) The Japan Society of Human Genetics and Springer-Verlag 2004

\begin{abstract}
We conducted a survey of malaria diagnoses and treatments in remote areas of Myanmar. Blood specimens from more than 1,000 people were collected by the finger-prick method, and $121(11 \%)$ of these people were found to be glucose-6-phosphate dehydrogenase (G6PD) deficient. Of these 121, 50 consented to analysis of the G6PD genome. We read the G6PD sequences of these subjects and found 45 cases of G6PD Mahidol (487G > A), two of G6PD Coimbra (592C > T), two of G6PD Union $(1360 \mathrm{C}>\mathrm{T}$ ), and one of G6PD Canton $(1376 \mathrm{G}>\mathrm{T})$. Taken together with data from our previous report, $91.3 \%(73 / 80)$ of G6PD variants were G6PD Mahidol. This finding suggests that the Myanmar population is derived from homogeneous ancestries and are different from Thai, Malaysian, and Indonesian populations.
\end{abstract}

H. Matsuoka $(\varangle) \cdot J$. Wang $\cdot$ M. Hirai $\cdot$ M. Arai $\cdot$ S. Yoshida Department of Medical Zoology, Jichi Medical School,

3311-1 Yakushiji, Minami-kawachi,

Tochigi 329-0498, Japan

E-mail: hiroyuki@jichi.ac.jp

Tel.: + 81-285-587339

Fax: +81-285-446489

T. Kobayashi

Department of Biomedical Chemistry,

Graduate School of Medicine,

The University of Tokyo, Tokyo, Japan

A. Jalloh

Department of Advanced Medical Science,

Nagoya University Graduate School of Medicine,

Showa, Nagoya, Japan

K. Lin

Parasitology Division, Department of Medical Research,

Upper Myanmar, Myanmar

F. Kawamoto

Faculty of Medicine, Institute of Scientific Research,

Oita University, Oita, Japan
Keywords Glucose-6-phosphate dehydrogenase deficiency $\cdot$ Mahidol $\cdot$ Malaria $\cdot$ Myanmar Primaquine

\section{Introduction}

Glucose-6-phosphate dehydrogenase (G6PD) deficiency is one of the most frequent hereditary abnormalities. The G6PD gene exists on the $\mathrm{X}$ chromosome distributed in 13 exons (Chen et al. 1991). Almost all G6PD deficiencies are caused by one amino acid change caused by a point mutation of the genomic DNA, and more than 100 molecular variants of the G6PD genotype have been identified (Fujii and Miwa 1998).

We introduced the rapid diagnosis method for malaria (Kawamoto and Billingsley 1992), a disease that kills more than 2,000,000 people worldwide annually. We also introduced the G6PD deficiency test (Hirono et al. 1998) in malaria endemic areas. Using these methods, patients are notified of the results of blood examination within $60 \mathrm{~min}$ and are able to receive antimalarial medicine including primaquine (Tantular et al. 1999). Primaquine can kill gametocytes, the sexual stage of malaria parasites, which are the cause of malaria transmission to mosquitoes. However, when G6PD-deficient persons take primaquine, a hemolytic attack can occur. Without G6PD, erythrocytes cannot prepare a sufficient amount of reduced pyridine nucleotide and reduced glutathione and cannot prevent oxidant attack by primaquine. Thus, primaquine should not be administered to malaria patients before confirming their G6PD activity.

We visited malaria endemic areas in Asian countries to introduce rapid methods of malaria diagnosis and G6PD test. By these activities, we have rediscovered two types of human malaria, Plasmodium minuta- and P. tenue-like parasites (Kawamoto et al. 2002), and also described ten G6PD variants including one new variant, G6PD Surabaya (1291G > A, V431M) (Iwai et al. 2001). 
In Myanmar, we previously reported that G6PD Mahidol (487G > A, G163S) was the main variant because we found 28 cases of G6PD Mahidol, one of G6PD Union $(1360 \mathrm{C}>\mathrm{T}, \mathrm{R} 454 \mathrm{C})$, and one of G6PD Canton $(1376 \mathrm{G}>\mathrm{T}, \mathrm{R} 459 \mathrm{~L})$ among 30 cases of G6PD-deficient subjects (Iwai et al. 2001). Over the past 5 years, we have continued this work in other areas of Myanmar. We improved the G6PD activity test because a better hydrogen carrier was developed with a new substrate, WST-8 (Tantular and Kawamoto 2003). L-Methoxy phenazine methosulfate, the new hydrogen carrier, is more photoresistant than phenazine methosulfate and can be used under normal light conditions. Moreover, the reaction of G6PD activity can be stopped by adding hydrochloride. Now we can detect not only complete G6PD deficiency but also partial G6PD deficiency (female heterozygote). After these developments, we were able to identify G6PD-deficient persons more easily (Jalloh et al. 2004) and have collected more information on G6PD variants in the Myanmar population.

\section{Materials and methods}

Between 1999 and 2003, we visited 16 sites in five divisions/states in Myanmar. They were the Mandalay Malaria Centre and three villages in Mandalay division; Sagain Malaria Centre, one health center, and one school in Sagaing division; three villages in Sittwe district; two villages in Thandwe district in Rakheine state; Yangon Malaria Centre in Yangon City; and three villages in Kaw Thaung disrict in Tanintharyi division. A small test unit was opened at each site, and local staff announced to the residents that we would perform rapid on-site examinations for malaria and G6PD activity. We examined about 100 people per day.

People were first registered by name, age, gender, and ethnicity. Next, three drops of blood were collected from the fingertip: one for malaria diagnosis, one for hemoglobin concentration, and one for G6PD test. Malaria was diagnosed by Acridine orange staining methods (Kawamoto and Billingsley 1992), and hemoglobin concentration was measured using a battery-powered HemoCue machine (Angelhorm, Sweden). Between 1999 and 2001, we used Hirono's method of detecting G6PD deficiency (Hirono et al. 1998). Between 2002 and 2003, we used a new diagnostic method (Tantular and Kawamoto 2003). Both methods gave the results of G6PD activity $30 \mathrm{~min}$ after taking blood.

When malaria patients were found and if their G6PD activity was normal, we gave them chloroquine and primaquine. If G6PD activity of the malaria patients was low, we gave them only chloroquine (Matsuoka et al. 1987). When we found a person whose G6PD activity was low, we asked the person if we could take $0.2 \mathrm{ml}$ of venous blood to read the G6PD genome. We explained the purpose of the investigation and received informed consent. Blood samples collected were stored at $4^{\circ} \mathrm{C}$ and brought back to Japan, and G6PD activity

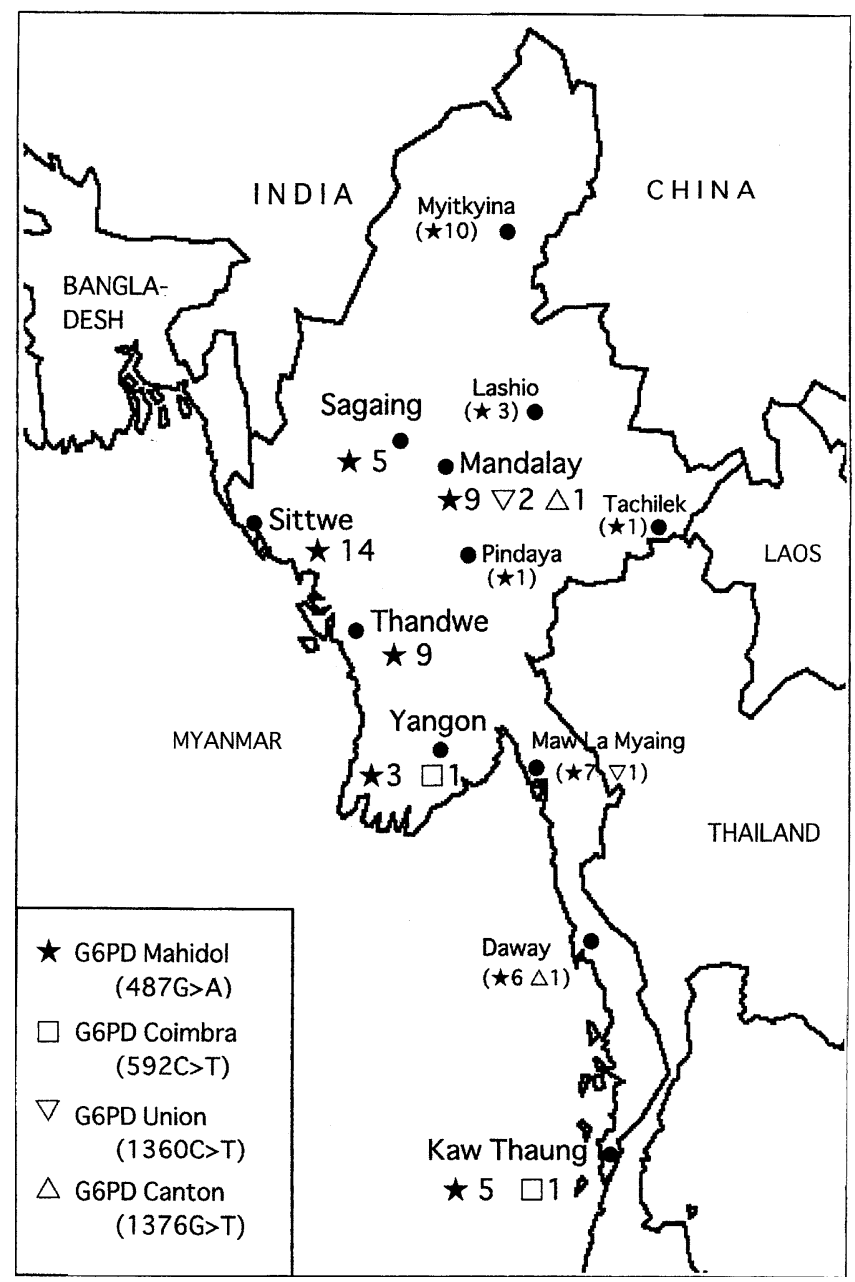

Fig. 1 Distribution of glucose-6-phosphate dehydrogenase (G6PD) variants in Myanmar. Each number indicates the number of G6PD-deficient cases confirmed by sequence analysis. Numbers in parentheses are from our previous report (Iwai et al. 2001)

was confirmed by another G6PD test developed by Fujii et al. (1984). Then the DNA sequence of G6PD was identified. Since genomic G6PD consists of 13 exons, we prepared primers for each exon (Hirono et al. 1994), amplified the exon by PCR, and read the DNA sequence (ABI PRISM 310; PE Biosystems, CT, USA). Both strands of each exon were sequenced. This study was approved by the Department of Health, Myanmar, and the ethical committees of Jichi Medical School.

\section{Results and discussion}

We surveyed malaria diagnosis and treatment in remote areas of Myanmar. Blood samples from more than 1,000 people were collected by the finger-prick method at 16 sites in five divisions/states (Fig. 1). Among those tested, we found more than 200 malaria cases and 121 cases of G6PD deficiency. These results are described elsewhere (Jalloh et al. 2004). During these activities, we received informed consent from 50 persons to analyze their 
$G 6 P D$ genome. We read $G 6 P D$ and found 45 cases $(90.0 \%)$ of G6PD Mahidol (487G > A) (Fig. 2), two of G6PD Coimbra $(592 \mathrm{C}>\mathrm{T})$, two of G6PD Union $(1360 \mathrm{C}>\mathrm{T})$, and one of G6PD Canton $(1376 \mathrm{G}>\mathrm{T})$. Taken together with data from our previous report (Iwai et al. 2001), 91.3\% (73/80) of G6PD variants were G6PD Mahidol (Table 1).

The Rakheine people, living on the west coast of Myanmar, are relatively isolated from the other people in Myanmar. We had a chance this time to research the Rakheine people because they lived in malaria endemic areas and agreed to be examined for malaria infection. We expected a unique G6PD variant from the Rakheine people; however, all deficiency patterns were G6PD Mahidol (14/14) (Table 1).

In Thailand, G6PD Viangchan $(871 \mathrm{G}>\mathrm{A})$ was the most common deficiency variant in the Thai population (Nuchprayoon et al. 2002). In that study, 21 cases of G6PD Viangchan $(67.7 \%)$ were found among 31 cases of G6PD deficiency, while G6PD Mahidol comprised only $9.7 \%$ (3/31). Ainoon et al. (2003) demonstrated nine $G 6 P D$ variants among 84 cases of G6PD deficiency in Malaysian Malays. The main variants were G6PD Viangchan (38.1\%), G6PD Mediterranean (27.4\%), and G6PD Mahidol (15.5\%). They concluded that Malaysian Malays had various ancestral contributions. From Indonesia, we reported that people in Flores Island showed a heterogeneous ancestry (Matsuoka et al. 2003 b) because we found five $G 6 P D$ variants among 15 G6PD-deficient persons. Flores Island belongs to the Sunda Archipelago where people might have come from Eurasian countries, African countries, Philippine Islands, and Pacific Islands. Historically, Flores Island might have accepted many tribes from different origins. Compared to data from Thailand, Malaysia, and Indonesia, the people in Myanmar are homogeneous in terms of $G 6 P D$ variants.

We did not detect G6PD Viangchan $(871 \mathrm{G}>\mathrm{A})$ in Myanmar. This variant is common in Laos $(100 \%)$ (Iwai et al. 2001), Thailand (67.7\%) (Nuchprayoon et al. 2002), and Malaysia (38.1\%) (Ainoon et al. 2003). We did not detect G6PD Mediterranean, a common variant in Mediterranean countries, Middle Eastern countries, Pakistan and India (Luzzatto and Notaro 2001), and Nepal (Matsuoka et al. 2003a). This result indicates that Myanmar people are absolutely different from the people of those countries. (a)
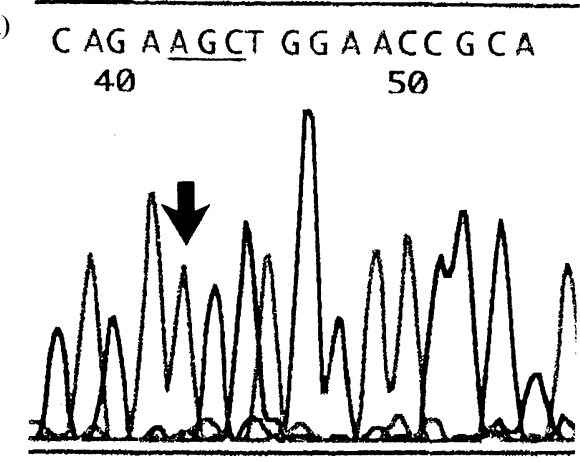

(b)

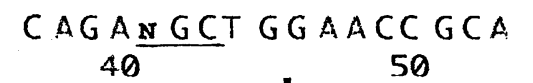

(c)
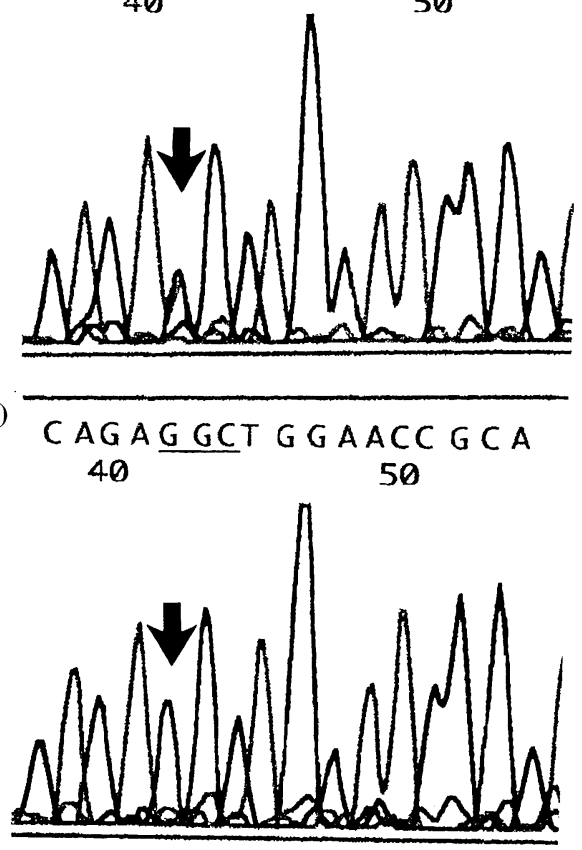

Fig. 2 a A part of the DNA sequence in exon 6 of a male with glucose-6-phosphate dehydrogenase (G6PD) Mahidol hemizygote. b A part of the DNA sequence in exon 6 of a female with G6PD Mahidol heterozygote. $\mathrm{c}$ A part of the DNA sequence in exon 6 of a normal control. Arrows show $487 \mathrm{G}>\mathrm{A}, 487 \mathrm{G}>\mathrm{G} / \mathrm{A}$, and $487 \mathrm{G}$, respectively

We found two cases of G6PD Coimbra $(592 \mathrm{C}>\mathrm{T})$ in Yangon and Kaw Thaung in the present study. G6PD Coimbra, which was first found in a Portuguese woman

Table 1 Glucose-6-phosphate dehydrogenase (G6PD) variants in ethnic groups in Myanmar (numbers in parentheses are from our previous report)

\begin{tabular}{|c|c|c|c|c|c|c|}
\hline Variant $^{\mathrm{a}}$ & Burmese & Rakhine & Shan & Kayin & Others & Total \\
\hline Mahidol & $30(+14)$ & 14 & $0(+2)$ & 1 & $0(+12)$ & $45(+28)$ \\
\hline Coimbra & 2 & 0 & 0 & 0 & 0 & 2 \\
\hline Union & $2(+1)$ & 0 & 0 & 0 & 0 & $2(+1)$ \\
\hline Canton & $0(+1)$ & 0 & 1 & 0 & 0 & $1(+1)$ \\
\hline Total & 34 (16) & 14 & $1(+2)$ & 1 & $0(+12)$ & $50(+30)$ \\
\hline
\end{tabular}

a Nucleotide change and amino acid change are G6PD Mahidol (487G > A, 163Gly > Ser), G6PD Coimbra (592C > T, 198Arg > Cys), G6PD Union (1360C > T, 454Arg > Cys), and G6PD Canton (1376G > T, 459Arg > Leu), respectively 
who lived in Coimbra, Portugal, is widely distributed in Europe and Asia but occurs with low frequencies (Corcoran et al. 1992). In Asia, this variant is said to distribute among aborigines (Tang et al. 1995). We found two cases of G6PD Coimbra among Malaysian aborigines (Iwai et al. 2001) and four cases on Flores Island, Indonesia (Matsuoka et al. 2003b). The discovery of G6PD Coimbra in Myanmar indicates that descendants of aborigines in Myanmar have become mixed with and live as Burmese.

Acknowledgements We thank Miss Maiko Nakamura and Miss Tomoko Yoshitomi for technical assistance. This work was supported by a grant-in-aid from the Japanese Ministry of Education, Science, Culture and Sports (14406026 to HM and 15406014 to FK).

\section{References}

Ainoon $\mathrm{O}, \mathrm{Yu} \mathrm{YH}$, Amir Muhriz AL, Boo NY, Cheong SK, Hamidah NH (2003) Glucose-6-phosphate dehydrogenase (G6PD) variants in Malaysian Malays. Hum Mutat 21:101

Chen EY, Cheng A, Lee A, Kuang WJ, Hillier L, Green P, Schlessinger D, Ciccodicola A, D'Urso M (1991) Sequence of human glucose-6-phosphate dehydrogenase cloned in plasmids and a yeast artificial chromosome. Genomics 10:792-800

Corcoran CM, Calabro V, Tamagnini G, Town M, Haidar B, Vulliamy TJ, Mason PJ, Luzzatto L (1992) Molecular heterogeneity underlying the G6PD Mediterranean phenotype. Hum Genet 88:688-690

Fujii H, Miwa S (1998) Red blood cell enzymes and their clinical application. Adv Clin Chem 33:1-54

Fujii H, Takahashi K, Miwa S (1984) A new simple screening method for glucose 6-phosphate dehydrogenase deficiency. Acta Haematol Jpn 47:185-188

Hirono A, Miwa S, Fujii H, Ishida F, Yamada K, Kubota K (1994) Molecular study of eight Japanese cases of glucose-6phosphate dehydrogenase deficiency by nonradioisotopic single-strand conformation polymorphism analysis. Blood 83:3363-3368

Hirono H, Fujii H, Miwa S (1998) An improved single-step screening method for glucose-6-phosphate dehydrogenase deficiency. Jpn J Trop Med Hyg 26:1-4
Iwai K, Hirono A, Matsuoka H, Kawamoto F, Horie T, Lin K, Tantular IS, Dachlan YP, Notopuro H, Hidayah NI, Salim AM, Fujii H, Miwa S, Ishii A (2001) Distribution of glucose-6phosphate dehydrogenase mutations in Southeast Asia. Hum Genet 108:445-449

Jalloh A, Tantular IS, Pusarawati S, Kawilarang AP, Kerong H, Lin K, Ferreira MU, Matsuoka H, Arai M, Kita K, Kawamoto F (2004) Rapid epidemiologic assessment of glucose-6-phosphate dehydrogenase (G6PD) deficiency in malaria-endemic areas in Southeast Asia using a novel diagnostic kit. Trop Med Int Health 9:615-623

Kawamoto F, Billingsley PF (1992) Rapid diagnosis of malaria by fluorescence microscopy. Parasitol Today 8:69-71

Kawamoto F, Win TT, Mizuno S, Lin K, Kyaw O, Tantular IS, Mason DP, Kimura M, Wongsrichanalai C (2002) Unusual Plasmodium malariae-like parasites in southeast Asia. J Parasitol 88:350-357

Luzzatto L, Notaro R (2001) Malaria. Protecting against bad air. Science 20:442-443

Matsuoka H, Ishii A, Panjaitan W (1987) Chemotherapeutic control trial of Plasmodium falciparum with a combination of chloroquine and primaquine on selective age group in a coastal village of North Sumatra, Indonesia. Jpn J Trop Med Hyg $15: 257-268$

Matsuoka H, Jichun W, Hirai M, Yoshida S, Arai M, Ishii A, Baral MP (2003a) Two cases of glucose-6-phosphate dehydrogenase deficient Nepalese belonging to the G6PD Mediterranean-type, not India-Pakistan sub-type but MediterraneanMiddle East sub-type. J Hum Genet 48:275-277

Matsuoka H, Arai M, Yoshida S, Tantular IS, Pusarawati S, Kerong H, Kawamoto F (2003b) Five different glucose-6phosphate dehydrogenase (G6PD) variants found among 11 G6PD-deficient persons in Flores Island, Indonesia. J Hum Genet 48:541-544

Nuchprayoon I, Sanpavat S, Nuchprayoon S (2002) Glucose-6phosphate dehydrogenase (G6PD) mutations in Thailand: G6PD Viangchan $(871 \mathrm{G}>\mathrm{A})$ is the most common deficiency variant in the Thai population. Hum Mutat 19:185

Tang TK, Huang WY, Tang CJ, Hsu M, Cheng TA, Chen KH (1995) Molecular basis of glucose-6-phosphate dehydrogenase (G6PD) deficiency in three Taiwan aboriginal tribes. Hum Genet 95:630-632

Tantular IS, Kawamoto F (2003) An improved, simple screening method for detection of glucose-6-phosphate dehydrogenase deficiency. Trop Med Int Health 8:569-574

Tantular IS, Iwai K, Khin-Lin, Basuki S, Horie T, Htay HH, Matsuoka H, Marwoto H, Wongsrichanalai C, Dachlan YP, Kojima S, Ishii A, Kawamoto F (1999) Field trials of a rapid test for G6PD deficiency in combination with a rapid diagnosis of malaria. Trop Med Int Health 4:245-250 